\title{
Presentismo e historia del tiempo presente: elementos para una discusión actual del quehacer historiográfico
}

Resumen: El artículo explora las reflexiones en torno a los presentismos y la historia del tiempo presente como telón de fondo del quehacer actual de los historiadores. Aborda las principales tesis de François Hartog y Hans Ulrich Gumbrecht sobre la experiencia presentista, caracteriza dicha perspectiva historiográfica en conexión con la vuelta del acontecimiento y profundiza en los aportes de tres autores que abogan por el estudio distanciado del presente. El texto cierra con un llamado a pensar la práctica historiográfica actual en función del orden del tiempo dominante como un ejercicio de recepción crítica de algunos debates de la teoría de la historia.

Palabras clave: historia del tiempo presente, presentismo, teoría de la historia, régimen de historicidad.

\section{Presentism and history of present time: elements for a current discussion of historiographic work}

Abstract: This article explores reflections on presentisms and the history of the present time as a backdrop to the current work of historians. It addresses the main theses of François Hartog and Hans Ulrich Gumbrecht on the presentism experience, characterizes this historiographic perspective in connection with the event's return, and delves into the contributions of three authors who advocate a distant study of the present. It finishes calling attention to think about current historiographic practice in terms of the order of the dominant time as an exercise in the critical reception of some debates on the theory of history.

Keywords: present time history, presentism, theory of history, regime of historicity.

\section{Presentismo e história do tempo presente: elementos para uma discussão atual do trabalho historio- gráfico}

Resumo: 0 artigo explora as reflexões em torno dos presentismos e da história do tempo presente como pano de fundo para o trabalho atual dos historiadores. Aborda as principais teses de François Hartog e Hans Ulrich Gumbrecht sobre a experiência presentista, caracteriza essa perspectiva historiográfica em conexão com o retorno do acontecimento e aprofunda as contribuições de três autores que defendem um estudo distanciado do presente. 0 texto se encerra com um chamado a pensar a prática historiográfica atual a partir da ordem do tempo dominante como um exercício de recepção crítica de alguns debates da teoria da história.

Palavras-chave: história do tempo presente, presentismo, teoria da história, regime de historicidade.

Cómo citar este artículo: Gabriel Samacá Alonso y Álvaro Acevedo Tarazona, "Presentismo e historia del tiempo presente: elementos para una discusión actual del quehacer historiográfico", Trashumante. Revista Americana de Historia Socia/ 19 [2022]: 208-230.

DOI: 10.17533/udea.trahs.n19a10

Fecha de recepción: 1 de octubre de 2020

Fecha de aprobación: 28 de julio de 2021

Gabriel Samacá Alonso: Doctor en Historia por El Colegio de México. Profesor de la Universidad Industrial de Santander. ORCID: 0000-0002-8319-2073.

Correo electrónico: gsamaca@colmex.mx

Álvaro Acevedo Tarazona: Doctor en Historia por la Universidad de Huelva. Profesor titular de la Universidad Industrial de Santander. ORCID: 0000-0002-3563-9213.

Correo electrónico: tarazona20@gmail.com 


\title{
Presentismo e historia del tiempo presente: elementos para una discusión actual del quehacer historiográfico*
}

\author{
Gabriel Samacá Alonso y Álvaro Acevedo Tarazona \\ Introducción
}

D esde hace algunas décadas, el presente dejó de ser un objeto exclusivo de las ciencias sociales para convertirse en materia de interés de la historia. Muestra de ello, es el desarrollo de la historia ambiental o de la globalización, las cuales intentan ofrecer respuestas a problemas acuciantes de la actualidad, como las migraciones masivas, el cambio climático y la desigualdad social. ${ }^{1}$ A nivel continental, las pesquisas sobre este "nuevo" ámbito tuvieron como trasfondo las transiciones a la democracia desde regímenes autoritarios y dictatoriales. Esta entrada al presente se dio especialmente a través de la recuperación de la memoria colectiva de las víctimas y dejó de lado la reflexión desde los fundamentos disciplinares. En tal sentido, cabe preguntarse si la teoría de la historia puede aportar a la comprensión de este fenómeno desde una reflexión sobre la experiencia de la temporalidad y sus posibles incidencias en las formas de hacer historia.

De esta forma, en las siguientes páginas se sostiene que la actual labor del historiador puede enriquecerse si se toma en cuenta la relación entre el régimen de historicidad y el régimen historiográfico. Para ello, se parte de la premisa de que "la historia en cuanto práctica social que trabaja con el tiempo debiera expresar el régimen de historicidad dominante en el que se inscribe". ${ }^{2}$ Las discusiones sobre

* Este artículo es resultado del proyecto de investigación "Resistencia de las producciones culturales audiovisuales y editoriales como alternativa de memoria poética del conflicto armado colombiano, 1987-2016". Proyecto Minciencias, Centro Nacional de Memoria Histórica,VIEUIS. Código: 8033, vigencia 2020-2022.

1. Jo Guldi y David Armitage, Manifiesto por la historia (Madrid: Alianza Editorial, 2016); Jürgen Osterhammel y Niels P. Petersson, Breve historia de la globalización. Del 1500 a nuestros días (Buenos Aires: Siglo XXI Editores, 2019).

2. María Inés Mudrovcic, "Cuando la historia se encuentra con el presente o lo que queda del "pasado histórico"”, En busca del pasado perdido. Temporalidad, historia y memoria, coords. María Inés Mudrovcic y Nora Rabotnikof (México: Universidad Nacional Autónoma de México / Siglo XXI Editores, 2013) 69. 
el tipo de historia que se practica hoy día se hallan íntimamente involucradas con la caracterización del "orden del tiempo" en que se vive. ${ }^{3}$ El quehacer historiográfico depende y expresa la articulación, el despliegue y las relaciones de aquello que se conoce como pasado, presente y futuro. En otras palabras, interesa subrayar el vínculo entre la escritura de la historia y la forma en que se conceptualizan las experiencias temporales.

Para desarrollar este planteamiento, el artículo se estructura en cuatro partes. La primera pretende dar cuenta de los principales argumentos de François Hartog, quien propone la existencia de una crisis del tiempo moderno y la emergencia de un régimen presentista de historicidad. Acto seguido, se aborda la obra del crítico literario e historiador alemán Hans Ulrich Gumbrecht, quien ha acuñado el concepto de lento presente para referirse a la misma problemática. ${ }^{4}$ En la tercera, se caracteriza la historia del tiempo presente (HTP), al hacer énfasis en el lugar del acontecimiento en la construcción de una definición no estrictamente metodológica de esta perspectiva historiográfica. En la cuarta, se sintetizan los aportes de Julio Aróstegui, Henry Rousso y Hugo Fazio Vengoa como referentes destacados de este campo de estudios. Este artículo puede ser entendido como un ejercicio de recepción crítica de una problemática que preocupa a la comunidad académica internacional y busca aportar a la necesaria reflexividad desde la disciplina en el contexto actual.

\section{Hartog o la crisis del tiempo: ¿un nuevo régimen de historicidad presentista?}

Para pensar las experiencias sociales de tiempo, la teoría de la historia se ha servido de la categoría de régimen de historicidad. Acuñado por François Hartog, este concepto se nutre de tres fuentes. En primer lugar, de la revitalización del vínculo entre antropología e historia que concluye la existencia de diferentes formas de historicidad en todas las sociedades. En segundo lugar, se encuentra el abordaje de las categorías metahistóricas koselleckianas de campo de experiencia y horizonte de expectativas para conceptualizar las particularidades del tiempo histórico. En tercer lugar, la discusión entre memoria e historia que, en el caso francés, derivó en un campo de investigación liderado por Pierre Nora. ${ }^{5}$ De esta forma, se puede entender como régimen de historicidad "una manera de engranar pasado, presente y futuro o de componer una mixtura de tres categorías [en la cual] uno de los tres compuestos es de hecho el dominante". ${ }^{6}$

3. Krzysztof Pomian, L'ordre du temps (París: Gallimard, 1984).

4. Sobre el itinerario intelectual de François Hartog, véase Aurelia Valero Pie, "François Hartog (n. 1946) o el contraste como método", Historia y método en el siglo XX, coords. Pilar Gilardi González y Martín F. Ríos Saloma (México: Universidad Nacional Autónoma de México, 2017) 81-104.

5. Christian Delacroix, "Genealogía de una noción”, Historicidades, dirs. Christian Delacroix y otros (Buenos Aires: Waldhuter Editores, 2010) 31-50.

6. François Hartog, Regímenes de historicidad. Presentismo y experiencias del tiempo (México: Universidad Iberoamericana, 2007) 15. 
De acuerdo con Hartog, Occidente ha experimentado tres grandes formas de articulación del tiempo histórico que han coexistido traslapándose de manera diferenciada. En el régimen clásico o antiguo predominaba el pasado como referente temporal, supeditando el cambio o movimiento histórico a la repetición y lo cíclico. $\mathrm{Su}$ expresión historiográfica fue la historia magistra vitae cuya materia fundamental fueron los exempla de los héroes, considerados semidioses, de los que se podían extraer enseñanzas moralizantes. ${ }^{7}$ En segundo lugar, como lo demostró Koselleck, desde mediados del siglo XVIII emergió una época de umbral (Sattelzeit), caracterizada por una aceleración de las experiencias temporales y la escisión del pasado respecto al futuro a partir de conceptos como progreso y revolución. ${ }^{8}$ El ser humano, como hacedor de historia, y el tiempo, como actor, se liberaron de la sujeción providencial para dar prelación al porvenir. En este contexto, emergió la historia, que, con pretensiones científicas, devino en un análisis histórico encargado de dar cuenta del pasado como un ente del que ya no se podían esperar moralejas. ${ }^{9}$

La tercera articulación corresponde a la crisis del régimen moderno, objeto de atención de Hartog, quien se pregunta por el tipo de orden del tiempo que se experimenta a finales del siglo XX.$^{10} \mathrm{~A}$ diferencia de lo que consideran algunos de sus críticos, cuando Hartog habla de "presentismo" no constata la cristalización de un nuevo régimen de historicidad, sino la existencia de una brecha temporal. En otros términos, señala una serie de síntomas de las crisis del orden futurista del tiempo que, en el marco de unas condiciones específicas, demandan una interpretación del tiempo actual en clave de deuda:

Así, el presente se ha extendido tanto en dirección del futuro como del pasado. Hacia el futuro: por los dispositivos de la precaución y de la responsabilidad, a través de la consideración de lo irreparable y de lo irreversible, por el recurso a la noción de patrimonio y a la de deuda, que reúne y da sentido al conjunto. Hacia el pasado: por la movilización de dispositivos análogos. La responsabilidad y el deber de memoria, la patrimonialización, lo imprescriptible, en tanto que deuda. Formulado a partir del presente y gravitando sobre él, este doble endeudamiento, tanto en dirección del pasado como del futuro marca la experiencia contemporánea del presente. ${ }^{11}$

7. Hartog, Regímenes de historicidad 50-102. El régimen heroico de historicidad se extendió hasta el siglo XVIII cobijando el orden cristiano del tiempo. De acuerdo con Reinhart Koselleck, en la historia maestra de la vida el campo de experiencia determinaba el horizonte de expectativa. Véase Reinhart Koselleck, Futuro pasado. Para una semántica de los tiempos históricos (Barcelona: Paidós, 1993) 41-66.

8. Elías José Palti, "Koselleck y la idea de Sattelzeit. Un debate sobre modernidad y temporalidad", Ayer 53 (2004): 63-74; Reinhart Koselleck, Aceleración, prognosis y secularización (Valencia: PreTextos, 2003).

9. Koselleck, Futuro pasado 287-332; Reinhart Koselleck, historia/Historia (Madrid: Editorial Trotta, 2010).

10. François Hartog, "El régimen moderno de historicidad puesto a prueba con las dos guerras mundiales", En busca del pasado perdido. Temporalidad, historia y memoria, coords. María Inés Mudrovcic y Nora Rabotnikof (México: Universidad Nacional Autónoma de México / Siglo XXI Editores, 2013) 51-65.

11. Hartog, Regímenes de historicidad 234. Cursiva en el original. 
La hipótesis presentista de Hartog se sintetiza en el posicionamiento de tres ámbitos que expresan la rearticulación de la experiencia temporal: el patrimonio, la memoria y la conmemoración, todos en función de la identidad. Tal forma de entender el presentismo entraña la pretensión de una historización inmediata de las experiencias basada en una obsesión por la posteridad cuya autoridad residiría en sí misma. ${ }^{12}$ Otro indicio del nuevo engranaje temporal es la sensación de desorientación que abunda en la opinión pública, la política y la academia, la cual hace cada vez más dificil imaginar cualquier proyección estructurada de futuro. En estas condiciones se erigen los principios de precaución y responsabilidad como formas de responder al quiebre del progreso que prevalece en la actualidad. ${ }^{13}$

Cuando el presente se pliega sobre sí mismo, extendiéndose, tornándose indefinido, ¿qué tipo de historia puede operar que atienda lo "irreparable, lo irremediable, lo incompensable, lo imperdonable, lo imprescriptible"? Desde esta perspectiva, el quehacer historiográfico estaría dominado por el desplazamiento de lo histórico por lo memorial desplegado en diferentes direcciones. Así, la idea de patrimonio se instala para reemplazar el monumento histórico gracias a la convergencia de la colección, la conservación y la restauración en función de una serie de preocupaciones que anticipan el futuro. Las instituciones culturales, oficiales o particulares, encargadas de la patrimonialización de las huellas materiales, así como de lo intangible, dedican sus esfuerzos y recursos a celebrar, imitar, conjurar, extraer su prestigio o visitar aquello que encaja en una definición cada vez más amplia de patrimonio.

Esta noción se expresa en los procesos de museificación y comercialización de la memoria fundados en la nostalgia por el desvanecimiento de lo acaecido. El afán de no dejar lugar para el olvido ha conducido a una ola patrimonial que pretende garantizar la transmisión del pasado a las nuevas generaciones a través de objetos, prácticas y significados de las generaciones predecesoras. Por otro lado, la rehabilitación, renovación y revitalización de diferentes espacios catalogados como patrimoniales plantea una estrecha relación con el territorio. Con la anuencia de organismos internacionales, profesionales de diferentes disciplinas posicionan la preservación de la cultura, pero también de la naturaleza, como una expresión patente del presentismo. Más que imitar el pasado, se procura responder a un futuro visto cada vez más como una amenaza. ${ }^{14}$

Si hay un concepto que defina un régimen presentista de historicidad es el de la memoria. En la esfera pública, este concepto arrolló al de historia al plantear nuevas formas de relacionamiento con el pasado a partir de la historización cotidiana del presente. Convertida en un asunto privado, la memoria atañe directamente a una "nueva economía de la identidad del yo" a partir de criterios psicológicos que derivan en un afán archivístico de almacenamiento. Con ella, no se retiene el pasado en función de un nuevo porvenir. Sin adentrarse en las profundidades de los

12. François Hartog, "La autoridad del tiempo", Historia Mexicana 58.4 (2009): 1438-1442.

13. Hartog, Regímenes de historicidad 235-237.

14. Hartog, Regímenes de historicidad 179-224. 
estudios sobre la memoria, es posible decir que hoy el vínculo con el pasado está marcado por una relación memorialista antes que historiográfica. Muestra de ello es el debilitamiento de la historia nacional como relato y marco de comprensión de lo acontecido y el fortalecimiento de una agenda investigativa en torno a los llamados "lugares de la memoria". ${ }^{15}$

Esta "edad memorial" se ha desplegado en tres direcciones. La primera remite a una "era de la conmemoración" manifiesta en una manía de recordar todo acontecimiento con un carácter patrimonial. ${ }^{16} \mathrm{El}$ segundo camino responde a la elaboración de políticas memoriales por parte de los Estados, agencias internacionales y asociaciones civiles que buscan el reconocimiento, la defensa o la transmisión de una memoria impedida y traumática. El marco de estas gestiones trasciende las fronteras nacionales al posicionar una serie de discusiones en torno a la pluralidad de memorias versus la historia oficial auspiciada por el Estado, debates epistemológicos sobre la distinción entre autenticidad y veracidad de los testimonios o disputas entre los actores que se movilizan en las luchas por la memoria. ${ }^{17}$

La última dirección atañe a los efectos mediatos de la segunda posguerra, específicamente los vínculos entre historia y justicia. A partir de Núremberg se asiste a una judicialización de la historia que ha trastocado el lugar, el alcance y las condiciones del quehacer historiográfico en la vida pública. Con el "deber de memoria" se está frente a la pérdida del poder de la historia tal y como se postuló durante el régimen moderno de historicidad, cuando pretendió sustituir la religión. Según Hartog, en estas circunstancias, el historiador deja de ser un analista de las experiencias de los seres humanos en el tiempo para ser un testigo experto ante los tribunales, donde podrá rendir testimonio y ayudar en la determinación de responsabilidades penales. El historiador también entra a competir en la reconstrucción del pasado con la voz de los testigos, quienes, en su calidad de víctimas de crímenes contra la humanidad, gozarían de mayor credibilidad como sobrevivientes. ${ }^{18}$

La ubicuidad de la memoria en la actual relación con el pasado tiene un alcance mayor en la redefinición del tiempo al que debe acoplarse toda actividad historiográfica. Por una parte, la demanda de memoria y sus implicaciones judiciales se instalan en relación con acontecimientos traumáticos de índole política que deben ser objeto de catarsis. ${ }^{19}$ Por otra, con ello se apunta directamente a un tiempo

15. Hartog, Regímenes de historicidad 148-170.

16. Las conmemoraciones de fines del siglo XX son objeto de interés para el historiador por la "erosión del modelo clásico de conmemoración nacional [y] una relación diferente con el pasado, más electiva que imperativa, abierta, plástica, viva, en perpetua elaboración”. Véase Pierre Nora, Pierre Nora en Les lieux de mémoire (Santiago de Chile: LOM Ediciones, 2009) 173.

17. François Hartog, Creer en la historia (Santiago de Chile: Ediciones Universidad Finis Terrae, 2014) 97-111.

18. François Hartog, Evidencia de la historia: lo que ven los historiadores (México: Universidad Iberoamericana, 2011) 183-224.

19. Dominick LaCapra, Representar el Holocausto. Historia, teoría, trauma (Buenos Aires: Prometeo Libros, 2007). 
nuevo que la historia no sabe o no puede atender: el de la imprescriptibilidad de los crímenes contra la humanidad. Este eterno presente, que interpela a víctimas, victimarios y a la sociedad en su conjunto, se asume como un "pasado que no pasa", que impone la búsqueda de responsabilidades, reparaciones y en general de justicia. La crisis del régimen moderno de historicidad ofrece como novedad una memoria magistra vitae. ${ }^{20}$

Para esta interpretación del presentismo lo que está en juego es el fin de la creencia en la historia. ${ }^{21}$ Con la clausura del futuro en forma de progreso, revolución o desarrollo, surge la incertidumbre como estado dominante en que el pasado tampoco ofrece ninguna clave para pensar el porvenir. El presente omnipresente y extendido despojó a la historia de sentido y al historiador de su posición privilegiada para hacer la historia. "La historia, aquella en la cual creyó el siglo XIX, aquella que se instaló como poder rector y como reserva de sentido o de sinsentido, se está alejando de nosotros y se está transformando en pasado, en una noción superada, caduca”. ${ }^{22}$ Este "presente monstruo", como lo llama Hartog, no impide que todavía se piense en términos de una posibilidad que advendrá, eso sí, cada vez más acorralada por lo instantáneo, lo efímero y lo inmediato con el presente como único horizonte.

Plausibles, o cuando menos sugerentes, los planteamientos de Hartog han sido criticados, entre otros, por el historiador Chris Lorenz, quien señaló las siguientes reservas: la ambigüedad en el uso del concepto de presentismo empleado unas veces como periodo histórico y otras como tipo ideal o herramienta heurística; el uso de una concepción lineal del tiempo que se trasluce en la sucesión de los regímenes de historicidad, lo que impide captar la experiencia simultánea de diferentes capas temporales que dan forma a los tiempos históricos; más que un abordaje antropológico, la obra de Hartog estaría más cerca de una historia de las ideas - historia intelectual, diría el autor- que del estudio de las experiencias sociales del tiempo; oblitera las críticas que se le han formulado a la modernidad, particularmente, al sesgo eurocéntrico, y, por último, su visión catastrofista del presente, que no es más que la inversión del futurismo del régimen moderno de historicidad, se traduce en planteamientos prescriptivos sobre la historia con un tono nostálgico dificil de ocultar. ${ }^{23}$

Con plena consciencia sobre las limitaciones de la propuesta de Hartog, cabe preguntarse si queda cerrada la hipótesis del presentismo para pensar el tiempo desde el cual se practica hoy la historia. Como se verá en el siguiente apartado, con la tradición alemana a cuestas y desde una perspectiva transdisciplinar, Hans Ulrich Gumbrecht lleva más lejos el planteamiento presentista, al sostener la existencia de un "lento presente" que impele a todas las ciencias sociales.

20. Hartog, Creer en la historia 93.

21. François Hartog, "Creer en la historia: ayer y hoy", Historia/fin de siglo, ed. Guillermo Zermeño Padilla (México: El Colegio de México, 2016) 27-58.

22. Hartog, Creer en la historia 36.

23. Chris Lorenz, "Out of Time? Some Critical Reflections on Francois Hartog's Presentism", Rethinking Historical Time. New Approaches to Presentism, eds. Marek Tamm y Laurent Olivier (Londres: Bloomsbury, 2019) 23-42. 


\section{Gumbrecht y el cronotopo presentista}

Desde Stanford, y en la intersección de crítica literaria, filosofia e historia, Gumbrecht intervino hace más de una década en el debate sobre la temporalidad del presente. Conocido por sus trabajos, que reivindican la corporeidad a nivel epistemológico, y crítico del paradigma hermenéutico en las humanidades, este autor difiere del análisis de Hartog en dos sentidos. ${ }^{24}$ Por un lado, asume la existencia de un nuevo marco global de las experiencias temporales que denomina como "lento presente", concepto con el que intenta asir más que resistir la contemporaneidad, la crítica cultural y la globalización. Por el otro, arraiga su reflexión en una lectura crítica de la teoría clásica del conocimiento centrada en la filosofia de la conciencia de origen cartesiano y el historicismo dominante en los siglos XIX y XX. ${ }^{25}$

Las transformaciones epistemológicas, históricas y sociológicas de la contemporaneidad son abordadas por este autor a partir de tres categorías: cronotopo, latencia y Stimmung. ${ }^{26}$ A partir de la obra de Mijaíl Bajtín, Hans Ulrich Gumbrecht conceptualiza el entrelazamiento de las coordenadas espacio-temporales con base en la categoría de cronotopo. ${ }^{27}$ Desde finales del siglo XVIII, la humanidad habría vivenciado un cronotopo historicista volcado hacia el futuro, objetivando el pasado con el propósito de dejarlo atrás. En diálogo en Koselleck, Gumbrecht recuerda que el presente puede ser entendido como un breve intersticio que erigió al sujeto cartesiano desde su exterioridad como amo y señor del mundo, al despojarse de su propia corporeidad, sensualidad y materialidad en busca de un conocimiento objetivo. ${ }^{28}$

Si bien el concepto de cronotopo enfatiza en la imbricación de tiempo y espacio, no da cuenta de las experiencias temporales en sí mismas. Para resolver tal vacío, propone asumir la temporalidad como vivencia a partir de "lo latente", esto es, las sensaciones del tiempo más allá de la mera cronología que se presenta como

24. Hans Ulrich Gumbrecht, En 1926: viviendo al borde del tiempo (México: Universidad Iberoamericana, 2004); Hans Ulrich Gumbrecht, Los poderes de la filología. Dinámicas de una práctica académica del texto (México: Universidad Iberoamericana, 2007).

25. Hans Ulrich Gumbrecht, "Nuestro amplio presente: sobre el surgimiento de una nueva construcción del tiempo y sus consecuencias para la disciplina de la historia", Historia/fin de siglo, ed. Guillermo Zermeño Padilla (México: El Colegio de México, 2016) 123-146.

26. A estas categorías se pueden sumar otras como producción y efectos de presencia, materialidades de la comunicación y campo no-hermenéutico que, en su conjunto, actualizan una nueva sustancialidad del ser.Véase Hans Ulrich Gumbrecht, Producción de presencia. Lo que el significado no puede transmitir (México: Universidad Iberoamericana, 2005).

27. El cronotopo es "[...] la conexión esencial de relaciones temporales y espaciales asimiladas artísticamente en la literatura [que] expresa el carácter indisoluble del espacio y tiempo (el tiempo como la cuarta dimensión del espacio)". Véase Mijaíl Bajtín, Teoría y estética de la novela. Trabajos de investigación (Madrid:Taurus, 1989) 237.

28. Hans Ulrich Gumbrecht, "De la legibilidad del mundo a su emergencia: una historia sobre el dualismo de las ciencias naturales y las ciencias del espíritu, con dos finales más bien abruptos", Cultura, política y modernidad, eds. Luz Gabriela Arango y otros (Bogotá: Universidad Nacional de Colombia, 1998) 33-61. 
exterior a los seres humanos. La preocupación por la sensualidad del tiempo y sus diferentes materializaciones le permite proponer que esta categoría comprende una historicidad que articula pasados, presentes y futuros dentro de un mismo cronotopo:

\begin{abstract}
Cuando hay un polizón en alguna parte, sentimos que algo (o alguien) está ahí pero que no podemos tocarlo o captarlo - y ese algo o alguien tiene una articulación material, lo que significa que ocupa espacio-. Obviamente no podemos decir de dónde, exactamente, viene nuestra certeza acerca de tal presencia, ni sabemos dónde, precisamente, está localizado lo latente. Y puesto que no conocemos la identidad del objeto o persona latente, no tenemos garantía de que podríamos reconocer tal ser, incluso si alguna vez se revelase. Más aun, lo que está latente puede sufrir cambios mientras permanece oculto. Más importante todavía: no tenemos razón, o al menos una razón sistemática, para creer que lo que está en un estado de latencia se muestre jamás, o al contrario, que no será simplemente olvidado algún día. ${ }^{29}$
\end{abstract}

En tal sentido, el ocultamiento, la emergencia o la quietud del tiempo se convierten en figuras de movimiento con las que se puede pensar cualquier cronotopo. En tercer lugar, la aprehensión de la dinámica temporal remite a la Stimmung, asumida como estado de ánimo o ambiente. Con este concepto, Gumbrecht apuntala la presencia de algo que se encuentra latente, lo cual emerge como un efecto que, si bien no se puede asir, analizar y descomponer, alude a una sensación que impacta en quienes lo perciben. ${ }^{30}$ La latencia se hace presente en y a través de una Stimmung, una atmósfera que envuelve a los sujetos provocando sensaciones de resistencia o deseo. ${ }^{31}$

Esta tríada conceptual sirve de entrada a sus principales argumentos en torno al presente ampliado. A primera vista, el cronotopo presentista no se distanciaría de la perspectiva de Hartog al coincidir en la prevalencia del presente respecto al pasado y el futuro. Sin embargo, se diferencia en dos aspectos puntuales. Por un lado, delimita con claridad el origen del presente a partir de su lectura sobre la segunda mitad del siglo XX; así, establece que el tiempo inmediatamente transcurrido después de 1945 representa el arranque del presente. Por el otro, asume, desde una posición sustancialmente diferente, la existencia de un presente ampliado desde el que invita a los investigadores, entre ellos a los historiadores, al aprovechamiento de las posibilidades que se abren con el nuevo cronotopo.

Después de 1945: la latencia como origen del presente puede ser entendida como una obra de historia cultural del tiempo presente que, con tono autobiográfico, condensa la atmósfera dominante en el mundo de la posguerra. A través de una lectura creativa y rica en matices de un universo documental heterodoxo, compuesto por poesía,

29. Hans Ulrich Gumbrecht, Después de 1945. La latencia como origen del presente (México: Universidad Iberoamericana, 2015) 27-28.

30. Aldo Mazzucchelli, "La producción de presencia y las humanidades. Entrevista a H.U. Gumbrecht", Nómadas 23 (2005): 185-191.

31. Gumbrecht, Después de 194538. 
cine, música, literatura, revistas y obras filosóficas, Gumbrecht cifra el surgimiento del presente amplio a partir del final de la Segunda Guerra Mundial. Los "topoi” que define para dar cuenta del ambiente que inauguró la conflagración son tres: primero, una sensación de inmovilidad - literal y metafórica - al terminar la guerra, cuando las fronteras no se podían cruzar y nuevos acontecimientos dejaron de ocurrir. Segundo, de forma paralela, la instalación del vacío y la desorientación en la existencia de los europeos, al cerrarse cualquier posibilidad de futuro a largo plazo, especialmente, aquellas expectativas fundadas ideológicamente. Tercero, el impacto que generó la bomba atómica impuso la necesidad o el anhelo de encontrar un espacio protegido ante lo que se denominó en su momento como "descarrilamiento de la historia", tras salirse del curso progresista de raíz moderna. ${ }^{32}$

Estas situaciones corresponden a tres dimensiones del Stimmung de la inmediata posguerra. Desde los cincuenta, más allá del breve paréntesis que avizoró un futuro clausurado con la invasión soviética a Hungría, se desplegaron los "efectos de latencia” en varias direcciones. Desde la izquierda se experimentó un desengaño sistemático que intentó ser compensado con la sensación de malestar generalizado de 1968. Ello derivó en una expectativa frustrada, cuyo puntillazo final sobrevino dos décadas más tarde con la caída del Muro de Berlín. Por otra parte, la experiencia de Hiroshima instaló la idea de futuro como amenaza, estabilizada gracias a la confrontación bipolar y la carrera armamentista que marcó la Guerra Fría. El paso del tiempo y el paulatino distanciamiento de los días de la guerra pusieron en el primer plano un pasado del que las generaciones mayores no querían hablar. Tal panorama indicaría la crisis del cronotopo historizante y a su vez la aparición de síntomas de una temporalidad de latencia que conduciría al nuevo cronotopo presentista. ${ }^{33}$

La metamorfosis del cronotopo historicista inició lentamente después de 1945 con el cierre de las posibilidades de futuro, la petrificación del pasado y el ensanchamiento constante del presente. La sucesión de etapas en la carrera ascendente hacia el progreso cedió a una sensación de estancamiento y predominio de las simultaneidades. Mientras que el pasado sobrecogió al presente a través de la melancolía, que no permite dejar atrás las experiencias (la imposibilidad de elaborar el duelo), la aceleración típicamente moderna devino en un enlentecimiento que condujo a la percepción de estar varados sin un norte al cual dirigirse. "Los dos movimientos, el de desplazar el futuro amenazante a un futuro lejano y el de rellenar el presente con múltiples pasados, convergen en la impresión de que, en el tiempo social postmoderno, el presente se dilata tanto que ningún futuro transportado al presente es capaz de convertirlo en pasado". ${ }^{34}$

Ante la virtualización de este presente, Gumbrecht reivindica, en un giro epistemológico, la búsqueda de la sustancialidad, esto es, la evasión hasta donde sea

32. Gumbrecht, Después de 1945 43-148.

33. Gumbrecht Después de 1945149.

34. Hans Ulrich Gumbrecht, Lento presente. Sintomatología del nuevo tiempo histórico (Madrid: Escolar y Mayo, 2010) 32. Cursiva en el original. 
posible de las mediaciones — incluidas las de la hermenéutica - para aproximarse a la experimentación sensorial y corpórea de la presencia en la vida cotidiana. Dado que el autor piensa en la actividad general de las humanidades y las artes, postula que la estética filosófica en los últimos años ha respondido a la pregunta por la sustancialidad. "Podría decirse que la experiencia estética es una experiencia situada en la frontera entre lo nouménico y lo fenoménico, que se trata de la experiencia del ser como sustancia y de cómo éste roza la conciencia humana". ${ }^{35}$ La salida estética a la dilatación del presente entraña una crítica frontal a quienes no pueden pensar de otra manera el tiempo histórico sino bajo los parámetros de la modernidad. De allí que se pregunte por lo que podría suceder si se aprecia el "lado positivo" del lento presente. ${ }^{36}$

Lejos de la nostalgia por la moderna historicidad, Gumbrecht lanza la pregunta por aquello que podrían hacer las humanidades en el nuevo cronotopo. En síntesis, considera la necesidad de que la universidad, en general, y el conocimiento social, en particular, se encarguen de producir pensamiento innovador a través de dos prácticas. Por una parte, la elaboración de "verdades desagradables" que, en lugar de reducir la complejidad, la incrementen. Por la otra, los humanistas deben incorporar la autorreflexión en su quehacer como parte de la crisis del paradigma moderno que escindió el sujeto del objeto. La potencial agenda tendría como eje el desplazamiento de la pregunta por el significado del mundo social, dominante bajo el imperio de la hermenéutica, a las condiciones de producción de significado bajo la denominación de una nueva arena de investigación: las "materialidades de la comunicación". 37

Para la historia, Gumbrecht plantea tres grandes retos basado en la premisa de que ya no es posible esperar ningún aprendizaje de esta. El primero consiste en tejer una nueva relación con el pasado, a fin de hacerlo más presente, es decir, convocarlo en lugar de interpretarlo y mediarlo. La apuesta es asir el pasado de la manera más directa y sensorialmente posible. En segundo lugar, aprecia en la actualidad un componente "somático" en el concepto de lo "humano" que se traduce, historiográficamente, en nuevos campos de escritura e investigación como las emociones, los sentimientos, las sensibilidades y un regreso a la espacialidad. Finalmente, cuando el pasado ya no es lo que era, es decir, Historia con mayúscula - de la que se esperaba sacar regularidades para proyectar en un futuro que tampoco se encuentra disponible-, invita a "vislumbrar en este cambio un enorme potencial de vivacidad e intensidad intelectuales". 38

Asumir los desafios que plantea una nueva forma de pensar el tiempo histórico hoy o mantener algunas banderas del régimen moderno de historicidad ante la embestida de la memoria son dos caminos y apuestas para el oficio del historiador.

35. Gumbrecht, Lento presente 106.

36. Gumbrecht, Lento presente 67.

37. Gumbrecht, Lento presente 107-134.

38. Gumbrecht, "Nuestro amplio presente" 132-133. 
Independientemente de la ruta que se tome, resulta imposible soslayar la reflexión que ofrece la teoría de la historia sobre el orden del tiempo actual.Aunque Hartog y Gumbrecht representen, hasta cierto punto, la vía francesa y alemana de esta discusión, es importante subrayar su convergencia respecto a la pertinencia de pensar el régimen de historicidad que condiciona el quehacer profesional del historiador. Más allá de las diferencias, que no son menores, sus interpretaciones son relevantes para asumir una posición sobre los nuevos enfoques que se perfilan como dominantes en la disciplina histórica y que remiten a las grandes problemáticas que se enfrentan en la actualidad. ${ }^{39}$

En el mismo orden, discusiones recientes en la teoría de la historia hablan de la entrada a una "fase superior" del presentismo. ${ }^{40}$ Bajo la denominación de actualismo, se conceptualiza una experiencia temporal "inauténtica" —en sentido heideggeriano- - propia de la era digital, en la que el presente no se mantiene estable y unívoco, pese a la lentitud con la que se despliega. Sin dirección alguna, el presente gira sobre sí mismo en busca de una permanente novedad. "El actualismo puede pensarse como una forma específica de temporalidad, es decir, un modo de articular pasado, presente y futuro que parece haber cobrado relevancia en nuestra contemporaneidad. Esa forma de articulación naturaliza el 'hoy', y por más que esté repleto de imágenes del pasado y del futuro, éstas no son capaces de transformar el horizonte". ${ }^{41}$ ¿Cómo se ha respondido desde el taller del historiador a esta situación en que la historia ya no es lo que era? ¿Es la HTP una respuesta crítica o un síntoma del orden del tiempo presentista/actualista en que se vive?

\section{Una breve caracterización de la historia del tiempo presente}

Seminarios, dosieres de revistas especializadas, eventos y decenas de libros publicados indican una suerte de boom sobre un campo, disciplina o perspectiva historiográfica conocida como historia del tiempo presente (HTP). Un reciente balance subraya la distinción que se debe hacer entre el presente como objeto de investigación y condición de la práctica historiográfica. A partir de ello, Eugenia Allier Montaño enlista las dificultades con que se tropiezan los investigadores al iniciarse en este nuevo territorio. Entre las más importantes, señala el problema de la denominación — historia reciente, actual, de pasados en conflicto, etcétera— ${ }^{42}$

39. Marek Tamm y Peter Burke, eds., Debating New Approaches to History (Londres: Bloomsbury, 2019).

40. Gisele Iecker de Almeida, "Futuro e história: análise da temporalidade atual", História da Historiografia 7.15 (2014): 51-69, doi: 10.15848/hh.v0i15.736.

41. Mateus Henrique Pereira y Valdei Lopes de Araujo, "Actualismo y presente amplio: breve análisis de las temporalidades contemporáneas”, Desacatos. Revista de Ciencias Sociales 55 (2017): 12-27, doi: $10.29340 / 55.1801$.

42. La historia actual o reciente está íntimamente ligada al dolor, el trauma y la búsqueda de justicia y verdad. En tal sentido, se inscribe fuertemente en el terreno político y ético y, en menor medida, en las discusiones epistemológicas de la historia. En contraste, la HTP se caracterizaría por abocar frontalmente la reflexión sobre la temporalidad. Para más información sobre la historia 
el lugar y peso de la experiencia vivida, la coexistencia del historiador y los sujetos de estudio, la centralidad del testimonio oral, la estrecha relación con los estudios sobre la memoria y, finalmente, los retos éticos que comporta la HTP dados los acontecimientos traumáticos que constituyen buena parte de su materia. ${ }^{43}$

Más allá de estas dificultades, se hace imperativo explicitar algunos rasgos que permiten caracterizar de manera general esta perspectiva historiográfica como respuesta al presentismo. El primero, remite a la progresiva institucionalización que experimentó en la posguerra, inicialmente como tarea de los Estados en el marco de la investigación sobre las guerras mundiales y luego como parte de los sistemas universitarios. La necesidad de responder al colaboracionismo bajo el régimen de Vichy en Francia, la experiencia nacionalsocialista en Alemania o las violaciones sistemáticas a los derechos humanos en las dictaduras militares del Cono Sur explican la realización de proyectos de investigación y formación de colecciones documentales que hicieron del presente y el pasado reciente un objeto de reflexión prioritario. ${ }^{44}$

En el proceso de configuración y desarrollo de la HTP resalta el nombre de François Bédarida (1926-2001), quien contribuyó hace varias décadas a sentar sus bases conceptuales. Con un origen francés, se pueden señalar cuatro pilares de esta forma de historiar que se han apropiado y adaptado en diferentes contextos. En primer lugar, como una crítica a la historia de cuño positivista que escindió el pasado del presente, la HTP rehabilita su dialéctica a partir de la consideración de este como el tiempo de la experiencia vivida. En segundo lugar, dada la contemporaneidad de su materia, esta corriente debe responder a una alta demanda social en disputa y diálogo con los medios de comunicación masiva y las ciencias sociales. ${ }^{45}$ En tercer lugar, metodológicamente, atribuye un lugar central al testimonio y la memoria de quienes tuvieron experiencias traumáticas, aunque no solo ellas, y el compromiso con un discurso de verdad. En cuarto lugar, el historiador ha de mantener un contrato con la verdad a pesar de las objeciones sobre la dificultad

reciente, véase María Inés Mudrovcic, ed., Pasados en conflicto. Representación, mito y memoria (Buenos Aires: Prometeo Libros, 2009) 13-31; Marina Franco y Florencia Levín, comps., Historia reciente. Perspectivas y desafios para un campo en construcción (Buenos Aires: Paidós, 2007).

43. Eugenia Allier Montaño, "Balance de la historia del tiempo presente. Creación y consolidación de un campo historiográfico", Revista de Estudios Sociales 65 (2018): 100-112, doi: 10.7440/ res65.2018.09.

44. Anne Pérotin-Dumon, "Liminar. Verdad y memoria: escribir la historia de nuestro tiempo", Historizar el pasado vivo en América Latina. http://etica.uahurtado.cl/historizarelpasadovivo/ es_contenido.php (15/09/2020); Walther L. Bernecker, "La historiografia del 'tiempo presente' en Alemania”, Historiografías. Revista de Historia y Teoría 15 (2018): 52-71, doi: 10.26754/ojs_ historiografias/hrht.2018152890; Luciano Alonso, "La 'Historia reciente' argentina como forma de Historia actual: emergencia, logros, ¿bloqueos?”, Historiografías. Revista de Historia y Teoría 15 (2018): 72-92, doi: 10.26754/ojs_historiografias/hrht.2018152891.

45. Jean-Pierre Rioux, "Historia del Tiempo Presente y demanda social", Cuadernos de Historia Contemporánea 20 (1998): 71-81. 
para distanciarse del problema de investigación y lo relacionado con la accesibilidad o la sobreabundancia de fuentes. ${ }^{46}$

La HTP se caracterizaría principalmente por asumir la reflexión sobre el tiempo histórico, entre otras razones, por la necesidad de sustentar la legitimidad de observación histórica del presente. En este contexto, desde los años setenta, la llamada "vuelta del acontecimiento" cobró relevancia como parte nodal de la definición de su ámbito de investigación. Al respecto, es necesario referenciar el trabajo seminal de Pierre Nora, quien sostuvo la existencia de un "acontecimiento monstruo" que, divulgado por los medios de comunicación masiva, devino en espectáculo por parte de las masas que creían vivenciarlo directamente. Entendido como "lo nuevo", el historiador del presente estaba llamado a dar cuenta de lo no acontecimental en lo acontecimental. La historia podría domeñar la fuerza disruptiva del acontecimiento al dotarlo de profundidad y fijarse en sus resonancias. Desde esta perspectiva, el acontecimiento no podía surgir de la nada, sino que debía reducirse a las estructuras que lo hacían posible delimitando sus contornos. Según Nora, "un acontecimiento es [...] un desgarro del tejido social que el mismo sistema tiene por función tejer". ${ }^{47}$

Aunque el ensayo de Nora es considerado como parte del desplazamiento de la historiografia francesa respecto a la historia serial, otros autores han replanteado esta perspectiva. ${ }^{48}$ Por ejemplo, François Dosse sostiene que, en el marco de una nueva historicidad de corte presentista, más que asistir a un retorno, se está frente a una mirada renovada del acontecimiento mismo, marcada por una doble dimensión: la de enigma y la reinterpretación constante. ${ }^{49}$ El acontecimiento remitiría a lo auténticamente singular, imprevisible e imprevisto del que es menester seguir sus huellas antes que sus causas. Más que una manifestación sometida al flujo del tiempo histórico, esta noción desestructura y reestructura la temporalidad al inaugurar nuevos horizontes. "El acontecimiento, por definición, no es reducible a su efectuación, en la medida que está siempre abierto hacia un devenir indefinido, por el cual su sentido va a metamorfosearse en el transcurso del tiempo". ${ }^{50}$

En cuanto lo acontecimental, que no se explica por las condiciones preexistentes, Humberto Beck se pregunta si no representa una respuesta diferente a las

46. El problema de las fuentes en la HTP oscila entre la superabundancia de materiales, la imposibilidad de su acceso y la centralidad de la oralidad. Véase Graciela de Garay, coord., Para pensar el tiempo presente. Aproximaciones teórico-metodológicas y experiencias empíricas (México: Instituto Mora, 2007). Los cuatro puntos nodales referidos se encuentran en: François Bédarida, "Definición, método y práctica de la Historia del Tiempo Presente", Cuadernos de Historia Contemporánea 20 (1998): 19-27.

47. Pierre Nora, "La vuelta del acontecimiento", Hacer la historia, vol. 1, dirs. Jacques Le Goff y Pierre Nora (Barcelona: Editorial Laia, 1985) 235.

48. Michel Trebitsch, "El acontecimiento, clave para el análisis del tiempo presente", Cuadernos de Historia Contemporánea 20 (1998): 29-40.

49. François Dosse, "El acontecimiento histórico entre Esfinge y Fénix", Historia y Grafía 21.41 (2013): 13-42.

50. François Dosse, El giro reflexivo de la historia. Recorridos epistemológicos y atención a las singularidades (Santiago de Chile: Ediciones Universidad Finis Terrae, 2012) 145-171, 231-256. 
tesis presentistas para pensar la relación con el tiempo. Para este autor, el acontecimiento -irrepresentable, aleatorio, impredecible e inconcluso- difiere del presentismo en cuanto que ofrece una apertura hacia futuros posibles al generar la oportunidad de pensar una historicidad abierta a cambios radicales que iluminarían la acción política en el presente y el porvenir. Evocando a Koselleck, asevera que "el acontecimiento sería [...] aquello que trasciende el "espacio de experiencia’, y al abrir el campo de la posibilidad histórica, produce de manera inesperada un nuevo y amplificado "horizonte de expectativa"." ${ }^{51}$

¿Se puede subsumir el acontecimiento a la corriente del tiempo histórico o es definitivamente el anuncio de la ruptura y de nuevos presentes? En síntesis, es posible encontrar dos grandes posiciones. Por un lado, se sostiene que el acontecimiento histórico, en cuanto momento axial, no puede ser aprehendido si se excluye de una duración mayor que, si bien modifica sustancialmente las reglas de reproducción del sistema, "es un elemento de la experiencia cuya explicación sólo encuentra significado si lo integramos en la estructura misma de la 'realidad a la que modifica". 52 Por otro lado, se tiene aquella posición que considera el acontecimiento como diferente de los hechos y los sucesos, portador de la posibilidad de generar cambios de estado en las condiciones que lo producen y capaz de modificar la misma estructura temporal. Sin tomar partido, lo cierto es que una definición de la HTP ha de considerar el acontecimiento como parte de su núcleo temático y conceptual. Ahora bien, para redondear este llamado a pensar el vínculo inextricable entre orden del tiempo y formas de hacer historia cabe preguntarse de qué manera se ha intentado historizar el presente.

\section{Tres vías para historizar el presente}

Para terminar este artículo se presentan las tesis fundamentales de tres historiadores del presente, quienes, con diferentes trayectorias y experiencias, ofrecen caminos particulares para practicar esta forma de historiar. Inscritos en tradiciones historiográficas, necesidades y preocupaciones diferentes, comparten un interés reflexivo sobre el papel de la historia en la actualidad, asumiendo el vínculo con el régimen de historicidad. Aunque no agotan la producción en este campo, su importancia radica, respectivamente, en la riqueza y operatividad de su reflexión (Julio Aróstegui), la complejización de la guerra como catástrofe decisiva en el surgimiento y desarrollo de la HTP (Henry Rousso) y, finalmente, en la valoración de la globalización como condición y tema de investigación más allá del predominio de lo traumático y memorialista en tal perspectiva historiográfica (Hugo Fazio Vengoa).

Conocedor de la historia del concepto, sus avatares institucionales y el contexto de emergencia en la Europa de la posguerra, Julio Aróstegui ha elaborado una su-

51. Humberto Beck, "El acontecimiento entre el presente y la historia", Desacatos. Revista de Ciencias Sociales 55 (2017): 44-59, doi: 10.29340/55.1803.

52. Julio Aróstegui, La historia vivida. Sobre la historia del presente (Madrid:Alianza Editorial, 2004) 97. 
gerente propuesta para trabajar la HTP. La definición de "la historia del presente", como la denomina el autor, corresponde a una historia "fluyente" de procesos sociales en curso, cuyos linderos temporales son flexibles en cuanto que se definen por la experiencia de las generaciones que interactúan en un momento determinado. Como "historia vivida", la HTP no se puede subsumir a un periodo histórico concreto y mucho menos definirse a partir de criterios metodológicos o contextuales. Aunque reconoce que esta corriente atañe a la memoria, el testigo, el testimonio y el acontecimiento, también sostiene que es mucho más que dichos elementos. ${ }^{53}$

¿De qué manera se puede conceptualizar una historia del presente y cómo opera? A partir de una antropologización del tiempo histórico, Aróstegui considera que el presente histórico anuda la actualidad con una duración que lo dota de espesor y permanencia. "El presente histórico es siempre un tiempo relativo, que coincide con la experiencia vital y con la experiencia intergeneracional de cada hombre, un tiempo de cronología móvil [...] Es fluyente y está indisociablemente ligado a la vida vivida por los sujetos históricos, que lo identifican en relación con ese momento axial de su partida". ${ }^{54}$ Si el presente histórico remite a una pluralidad temporal que converge en el tiempo vivido, es posible emprender una delimitación historiográfica de su campo de acción a partir de dos definiciones, la de los linderos cronológicos, con base en las generaciones que interactúan en el "ahora", y la de su origen, a partir de un acontecimiento axial que da a las cosas un nuevo curso y dota de sentido al presente. ${ }^{55}$

Definir la HTP como historia vivida pone el acento en las experiencias que las diferentes generaciones tienen del presente histórico. El autor fija su atención en la manera como se da dicha vivencia, la cual no es otra que la interacción de generaciones que coexisten en la coetaneidad. En un presente específico, convergen tres grupos etarios: los antecesores, los activos y los sucesores. La complejidad del presente definido intergeneracionalmente reside en que cada generación transita por los tres estados, aunque solo la activa está en capacidad de marcar el ritmo histórico que caracteriza cada presente, siempre en relación con los otros dos grupos. Esta perspectiva abre la posibilidad de fijar un tiempo sin limitarse a lo cronológico y sitúa a los sujetos en un entorno histórico más amplio. ${ }^{56}$

Metodológicamente, el historiador español ofrece dos criterios para investigar el presente. Por una parte, es posible emprender una "biografia colectiva generacional" al registrar la trayectoria histórica de una generación en sus tres momentos o estadios. Por otra, la HTP ha de apuntar a la historización de la experiencia propia en dos niveles interrelacionados: el subjetivo, a través de la racionalización de la experiencia vivida por una generación con la objetivación de la memoria, y el objetivo, en el que construye un discurso historiográfico de las vivencias propias

53. Aróstegui 19-61.

54. Aróstegui 102. Cursiva en el original.

55. Aróstegui 63-107.

56. Aróstegui 109-134. 
a través de su sistematización y tematización. "La historización opera una intermediación entre el tiempo privado y el público. Y tiene que constituirse como escritura, sea cual sea su carácter y el soporte que la materialice". ${ }^{57}$

En segundo lugar, destaca la obra de Henry Rousso, quien emprendió una crítica sistemática a la definición metodológica de la HTP, y más concretamente a lo que llama "criterios constantes", entre ellos, un periodo móvil, la reserva política, la centralidad del testigo o el carácter inconcluso. ${ }^{58}$ Este historiador francés ha sostenido la presencia de la contemporaneidad a lo largo de la historia y retoma cómo la dialéctica entre presente y pasado estuvo en el centro de la configuración de la ciencia histórica moderna. En su opinión, luego de la Primera Guerra Mundial se instaló la necesidad de que la historia diera sentido al conflicto que acababa de terminar con el fin de ayudar a salir del traumatismo. Entre los años veinte y treinta del siglo pasado habrían emergido todas las piezas que han identificado la HTP: la figura del historiador experto, el testigo como víctima, las discusiones en torno a la objetividad histórica, la tensión entre historizar con rigor, la empatía con las víctimas y la prelación del testimonio, entre otras. Tales elementos remitían al acontecimiento traumático o "última catástrofe" como tema de investigación fundamental de esta práctica historiográfica. ${ }^{59}$

Aunque sus principales rasgos se perfilaron en los albores del siglo XX, Rousso reconoce algunas especificidades posteriores a 1945. Entre ellas, destaca el tipo de acontecimiento que representó la Segunda Guerra Mundial, cuya barbarie reubicó el presente como un pasado cercano marcado por la culpabilidad y no como parte de un contínuum de progreso. A partir de sus estudios sobre el colaboracionismo francés bajo el régimen de Vichy, este autor elaboró una agenda investigativa centrada en una historia social de la memoria de la catástrofe, inicialmente bajo el influjo de la propuesta de Nora, pero luego dirigida al análisis de la relación entre derecho, historia y justicia. ${ }^{60}$ En su quehacer, articuló el estudio de las representaciones de los acontecimientos traumáticos con las reparaciones, indemnizaciones y conmemoraciones que tuvieron como eje las víctimas. Más recientemente, sus estudios devienen en el análisis de la judicialización de la historia. ${ }^{61}$

Desde esta perspectiva, la HTP es la historia de la última catástrofe, generalmente bélica o de violencia extrema que, en su configuración a lo largo del siglo XX, fue el resultado de una dialéctica entre pasado y presente advertida por Marc Bloch. Es una historia marcada por la tensión entre la mirada distanciada, propia de todo conocimiento histórico, y la urgencia de comprender lo que se

57. Aróstegui 186,134-193. Cursiva en el original.

58. Henry Rousso, La última catástrofe. La historia, el presente, lo contemporáneo (Santiago de Chile: Centro de Investigaciones Diego Barros Arana / Editorial Universitaria, 2018) 205-221.

59. Rousso, La última catástrofe 85-110.

60. Henry Rousso, "Los dilemas de una memoria europea", Historicidades, dirs. Christian Delacroix y otros (Buenos Aires: Waldhuter Editores, 2010) 229-249.

61. Henry Rousso, "La trayectoria de un historiador del tiempo presente, 1975-2000", Historizar el pasado vivo en América Latina. www.historizarelpasadovivo.cl/downloads/rousso.pdf(15/03/2020). 
presenta como incomprensible. En cuanto práctica que ganó su lugar en el mundo académico, se ha debatido entre la exigencia de recuerdo y la necesidad de olvido, así como en la inevitable asunción de la subjetividad del historiador que no puede falsear los hechos o guardar silencio por razones políticas. Para Rousso, la HTP se erige como una respuesta o antídoto al nuevo régimen de historicidad presentista: "hacer la historia del tiempo presente es postular que tal presente tiene un espesor, una profundidad, que no se reduce a una suma de instantáneas tomadas al vuelo. Como toda buena historia, se trata de restituir una genealogía, de insertar el acontecimiento en una duración, de proponer un orden de inteligibilidad que intente escapar de la emoción del instante". ${ }^{62}$

Con excepción del Cono Sur, y más recientemente de México, en Latinoamérica la reflexión sobre la HTP apenas llama la atención de los investigadores. En Colombia, destaca el nombre de Hugo Fazio Vengoa, quien lleva más de una década introduciendo estos debates en el medio intelectual nacional. La importancia de su trabajo radica en la apropiación de las discusiones europeas como parte del interés por tender puentes entre la disciplina histórica, la ciencia política y las relaciones internacionales. Para ello, inscribe su producción en la discusión sobre el tiempo histórico, al diferenciar el presente de la actualidad y la HTP de la llamada historia reciente. Fazio Vengoa pone el acento en las múltiples duraciones del presente histórico y los diferentes estratos temporales, cadencias y reverberaciones que lo constituyen.

Uno de sus principales aportes a la discusión consiste en relievar la dimensión espacial del nuevo régimen de historicidad presentista. La comprensión del horizonte temporal pasa por trascender la escala internacional, de manera que esta perspectiva historiográfica también se configura inevitablemente en un orden global. Al no considerar las tesis de una aldea global homogénea, hace hincapié en las resonancias y correlaciones de los acontecimientos planetarios en grados e intensidades disímiles que devienen en una multiplicidad de presentes históricos. Según el autor, la "modernidad global", como conceptualiza la actualidad, fue posible gracias a la concurrencia de procesos como la tercera revolución industrial, la emergencia de los medios de comunicación masiva, la extensión del mercado planetario, los procesos de individuación y la solidaridad internacional. ${ }^{63}$

Junto a la tesis de una historia global del presente, que recoge algunos desarrollos historiográficos en clave transnacional, Fazio Vengoa propone operativizar cronológicamente dicha modalidad del tiempo definiendo el momento axial que le dio origen, así como una periodización que abarca los últimos cincuenta años. Respecto a la génesis, considera que el presente histórico emerge en el cronotopo de 1968, cuando las características fundamentales de la globalización se plantearon por primera vez. Particularmente, identifica tendencias económicas, políticas y sobre todo culturales que trazaron un nuevo mundo más allá de lo nacional a través

62. Rousso, La última catástrofe 199.

63. Hugo Fazio Vengoa, La historia y el presente en el espejo de la globalización (Bogotá: Universidad de los Andes, 2008). 
de una progresiva sincronía que cubrió varios continentes. En cuanto a la periodización, sugiere cuatro momentos que resuelven la discusión en torno a fechas emblemáticas: 1968-1989, 1989-1997, 1997-2005 y 2005 hasta hoy. ${ }^{64}$

Con base en ello, el autor plantea que la HTP es aquella que se interesa por "inscribir el presente en las profundidades y espesuras del tiempo histórico", que procede retrospectivamente desde la actualidad para reconstruir la cadencia de sus dinámicas sustanciales. ${ }^{65}$ Esta propuesta piensa el presente más allá del boom memorialista en torno al acontecimiento traumático de la guerra. La obra empírica de Fazio Vengoa se restringe al estudio de las décadas de los setenta y ochenta con énfasis en los procesos económicos y políticos que, desafortunadamente, todavía se anclan en una visión clásica de la globalización y se alejan de la reflexión historiográfica a la que invitó. ${ }^{66}$ Este aspecto no resta importancia a su preocupación por la densidad del presente histórico basado, entre otras fuentes, en la apropiación crítica de la obra de Aróstegui y buena parte de los autores referenciados páginas arriba.

\section{A manera de cierre}

Recientemente, Guillermo Zermeño Padilla advirtió la necesidad de evitar la confusión entre presentismo e historia del tiempo presente, dado el frecuente traslape de los dos conceptos, que impide una correcta comprensión de su relación. Para el historiador mexicano, la HTP sería más un síntoma que una resistencia al nuevo régimen de historicidad. ${ }^{67}$ En contraste, Rousso sostiene que sí es una respuesta al presentismo al inscribirse en la tradición crítica de la historia moderna, lo que no obsta para reconocer sus especificidades teóricas y metodológicas. Estas dos posiciones evidencian la dificultad para construir un consenso sobre el vínculo entre los regímenes de historicidad e historiográficos en que se halla actualmente el historiador. Incluso, el debate sobre la temporalidad bajo la que ahora se vive introduce una categoría como la de "actualismo" con el fin de poner en duda la fuerza reflexiva de la tesis presentista.

Conscientes de la naturaleza abierta del debate sobre la temporalidad en que nos encontramos, este artículo asume la existencia de una crisis del orden temporal moderno que podría enfrentarse a partir de las herramientas que la historia acuñó a lo largo de su constitución disciplinar en los dos últimos siglos. Aunque es innegable el peso de la memoria en la relación con el pasado, apelamos a una

64. Hugo Fazio Vengoa, El presente histórico: una mirada panorámica (1968-2009) (Bogotá: Universidad de los Andes, 2009).

65. Hugo Fazio Vengoa, La historia del tiempo presente: historiografía, problemas y métodos (Bogotá: Universidad de los Andes, 2010).

66. Hugo Fazio Vengoa, Los setenta convulsionan el mundo. Irrumpe el presente histórico (Bogotá: Universidad de los Andes, 2014); Hugo Fazio Vengoa, El mundo en los ochenta: ¿universalismo vs. globalidad? (Bogotá: Universidad de los Andes, 2015).

67. Guillermo Zermeño Padilla, "Discusión general”, Desacatos. Revista de Ciencias Sociales 55 (2017): 81, doi: $10.29340 / 55.1805$. 
mirada crítica y alejada de la melancolía de una supuesta edad dorada de la disciplina. En el ámbito historiográfico, se apuesta por una apropiación de los aportes de las diferentes perspectivas de la HTP, al concebirla como respuesta crítica al presentismo, siempre y cuando se practique con rigurosidad y cautela respecto a las modas que están al acecho. Particularmente, se advierte una gran potencialidad para el desarrollo de trabajos en áreas como la historia social de la memoria y las maneras como se han representado en diferentes contextos acontecimientos como 1968 o 1989, entre muchas otras opciones.

La adaptación al nuevo cronotopo, como plantea Gumbrecht, pasa por considerar los vínculos entre el quehacer historiográfico y la reflexión teórica sobre el tiempo histórico en que se realiza. En tal sentido, además de preguntarse por los acontecimientos axiales que darían origen a los diferentes presentes históricos y sus entrelazamientos nacionales/globales, se reitera la invitación a pensar en plural el orden del tiempo en que se vive ahora para ejercer como historiadores. Un primer paso en esta dirección podría ser el de aproximarse a los debates en torno a los presentismos, las distintas maneras de historizar el presente y sus imbricaciones. Finalmente, se plantea una pregunta que el mismo Hartog formuló y que anuda el sentido de este escrito: "si entramos en un régimen 'presentista', ¿qué tipo de historia ya no se puede hacer y, al mismo tiempo, qué historia se podría hacer?”. ${ }^{68}$

\section{Bibliografía}

Allier Montaño, Eugenia. "Balance de la historia del tiempo presente. Creación y consolidación de un campo historiográfico”. Revista de Estudios Sociales 65 (2018): 100-112. Doi: 10.7440/res65.2018.09.

Alonso, Luciano. “La 'Historia reciente' argentina como forma de Historia actual: emergencia, logros, ¿bloqueos?”. Historiografías. Revista de Historia y Teoría 15 (2018): 72-92. Doi: 10.26754/ojs_historiografias/hrht.2018152891.

Aróstegui, Julio. La historia vivida. Sobre la historia del presente. Madrid: Alianza Editorial, 2004.

Bajtín, Mijaíl. Teoría y estética de la novela. Trabajos de investigación. Madrid:Taurus, 1989.

Beck, Humberto. "El acontecimiento entre el presente y la historia". Desacatos. Revista de Ciencias Sociales 55 (2017): 44-59. Doi: 10.29340/55.1803.

Bédarida, François. "Definición, método y práctica de la Historia del Tiempo Presente”. Cuadernos de Historia Contemporánea 20 (1998): 19-27.

Bernecker, Walther L. "La historiografia del 'tiempo presente' en Alemania”. Historiografías. Revista de Historia y Teoría 15 (2018): 52-71. Doi: 10.26754/ ojs_historiografias/hrht.2018152890.

De Almeida, Gisele Iecker. "Futuro e história: análise da temporalidade atual”. História da Historiografia 7.15 (2014): 51-69. Doi: 10.15848/hh.v0i15.736.

68. Christian Delacroix y otros, "Sobre la noción de régimen de historicidad: entrevista con François Hartog", Historicidades, dirs. Christian Delacroix y otros (Buenos Aires:Waldhuter Editores, 2010) 155. 
Delacroix, Christian. “Genealogía de una noción”. Historicidades. Dirs. Christian Delacroix y otros. Buenos Aires: Waldhuter Editores, 2010.

Delacroix, Christian y otros. "Sobre la noción de régimen de historicidad: entrevista con François Hartog”. Historicidades. Dirs. Christian Delacroix y otros. Buenos Aires: Waldhuter Editores, 2010.

Dosse, François. "El acontecimiento histórico entre Esfinge y Fénix". Historia y Grafía 21.41 (2013): 13-42.

. El giro reflexivo de la historia. Recorridos epistemológicos y atención a las singularidades. Santiago de Chile: Ediciones Universidad Finis Terrae, 2012.

Fazio Vengoa, Hugo. El mundo en los ochenta: ¿universalismo vs. globalidad? Bogotá: Universidad de los Andes, 2015.

. El presente histórico: una mirada panorámica (1968-2009). Bogotá: Universidad de los Andes, 2009.

- La historia del tiempo presente: historiografía, problemas y métodos. Bogotá: Universidad de los Andes, 2010.

. La historia y el presente en el espejo de la globalización. Bogotá: Universidad de los Andes, 2008.

. Los setenta convulsionan el mundo. Irrumpe el presente histórico. Bogotá: Universidad de los Andes, 2014.

Franco, Marina y Florencia Levín. Comps. Historia reciente. Perspectivas y desafíos para un campo en construcción. Buenos Aires: Paidós, 2007.

Garay, Graciela de. Coord. Para pensar el tiempo presente. Aproximaciones teórico-metodológicas y experiencias empíricas. México: Instituto Mora, 2007.

Guldi, Jo y David Armitage. Manifiesto por la historia. Madrid:Alianza Editorial, 2016.

Gumbrecht, Hans Ulrich. "De la legibilidad del mundo a su emergencia: una historia sobre el dualismo de las ciencias naturales y las ciencias del espíritu, con dos finales más bien abruptos”. Cultura, política y modernidad. Eds. Luz Gabriela Arango y otros. Bogotá: Universidad Nacional de Colombia, 1998.

. Después de 1945. La latencia como origen del presente. México: Universidad Iberoamericana, 2015.

. En 1926: viviendo al borde del tiempo. México: Universidad Iberoamericana, 2004.

. Lento presente. Sintomatología del nuevo tiempo histórico. Madrid: Escolar y Mayo, 2010.

. Los poderes de la filología. Dinámicas de una práctica académica del texto. México: Universidad Iberoamericana, 2007.

. "Nuestro amplio presente: sobre el surgimiento de una nueva construcción del tiempo y sus consecuencias para la disciplina de la historia". Historia/fin de siglo. Ed. Guillermo Zermeño Padilla. México: El Colegio de México, 2016.

. Producción de presencia. Lo que el significado no puede transmitir. México: Universidad Iberoamericana, 2005. 
Hartog, François. Creer en la historia. Santiago de Chile: Ediciones Universidad Finis Terrae, 2014.

. "Creer en la historia: ayer y hoy". Historia/fin de siglo. Ed. Guillermo Zermeño Padilla. México: El Colegio de México, 2016.

. "El régimen moderno de historicidad puesto a prueba con las dos guerras mundiales". En busca del pasado perdido. Temporalidad, historia y memoria. Coords. María Inés Mudrovcic y Nora Rabotnikof. México: Universidad Nacional Autónoma de México / Siglo XXI Editores, 2013.

. Evidencia de la historia: lo que ven los historiadores. México: Universidad Iberoamericana, 2011.

."La autoridad del tiempo". Historia Mexicana 58.4 (2009): 1419-1445.

- Regímenes de historicidad. Presentismo y experiencias del tiempo. México: Universidad Iberoamericana, 2007.

Koselleck, Reinhart. Aceleración, prognosis y secularización.Valencia: Pre-Textos, 2003.

. Futuro pasado. Para una semántica de los tiempos históricos. Barcelona: Paidós, 1993.

. historia/Historia. Madrid: Editorial Trotta, 2010.

LaCapra, Dominick. Representar el Holocausto. Historia, teoría, trauma. Buenos Aires: Prometeo Libros, 2007.

Lorenz, Chris. "Out of Time? Some Critical Reflections on Francois Hartog's Presentism". Rethinking Historical Time. New Approaches to Presentism. Eds. Marek Tamm y Laurent Olivier. Londres: Bloomsbury, 2019.

Mazzucchelli, Aldo. "La producción de presencia y las humanidades. Entrevista a H.U. Gumbrecht”. Nómadas 23 (2005): 185-191.

Mudrovcic, María Inés. "Cuando la historia se encuentra con el presente o lo que queda del "pasado histórico"”. En busca del pasado perdido. Temporalidad, historia y memoria. Coords. María Inés Mudrovcic y Nora Rabotnikof. México: Universidad Nacional Autónoma de México / Siglo XXI, 2013. . Ed. Pasados en conflicto. Representación, mito y memoria. Buenos Aires: Prometeo Libros, 2009.

Nora, Pierre. "La vuelta del acontecimiento". Hacer la historia. Volumen 1. Dirs. Jacques Le Goff y Pierre Nora. Barcelona: Editorial Laia, 1985.

. Pierre Nora en Les lieux de mémoire. Santiago de Chile: LOM Ediciones, 2009.

Osterhammel, Jürgen y Niels P. Petersson. Breve historia de la globalización. Del 1500 a nuestros días. Buenos Aires: Siglo XXI Editores, 2019.

Palti, Elías José. "Koselleck y la idea de Sattelzeit. Un debate sobre modernidad y temporalidad". Ayer 53 (2004): 63-74.

Pereira, Mateus Henrique y Valdei Lopes de Araujo. “Actualismo y presente amplio: breve análisis de las temporalidades contemporáneas". Desacatos. Revista de Ciencias Sociales 55 (2017): 12-27. Doi: h10.29340/55.1801.

Pérotin-Dumon, Anne. "Liminar.Verdad y memoria: escribir la historia de nuestro tiempo". Historizar el pasado vivo en América Latina. http://etica.uahurta- 
do.cl/historizarelpasadovivo/es_contenido.php (15/09/2020).

Pomian, Krzysztof. L'ordre du temps. París: Gallimard, 1984.

Rioux, Jean-Pierre. "Historia del Tiempo Presente y demanda social". Cuadernos de Historia Contemporánea 20 (1998): 71-81.

Rousso, Henry. "La trayectoria de un historiador del tiempo presente, 1975-2000". Historizar el pasado vivo en América Latina. www.historizarelpasadovivo. cl/downloads/rousso.pdf (15/03/2020).

. La última catástrofe. La historia, el presente, lo contemporáneo. Santiago de Chile: Centro de Investigaciones Diego Barros Arana / Editorial Universitaria, 2018.

. "Los dilemas de una memoria europea". Historicidades. Dirs. Christian Delacroix y otros. Buenos Aires: Waldhuter Editores, 2010.

Tamm, Marek y Peter Burke. Eds. Debating New Approaches to History. Londres: Bloomsbury, 2019.

Trebitsch, Michel. "El acontecimiento, clave para el análisis del tiempo presente”. Cuadernos de Historia Contemporánea 20 (1998): 29-40.

Valero Pie, Aurelia. "François Hartog (n. 1946) o el contraste como método". Historia y método en el siglo XX. Coords. Pilar Gilardi González y Martín F. Ríos Saloma. México: Universidad Nacional Autónoma de México, 2017.

Zermeño Padilla, Guillermo. "Discusión general". Desacatos. Revista de Ciencias Sociales 55 (2017): 74-87. Doi: 10.29340/55.1805. 